2007-01-01

\title{
A Peroxisomal Acyltransferase in Mouse Identifies a Novel Pathway for Taurine Conjugation of Fatty Acids.
}

\author{
Sarah-Jayne Reilly \\ Karolinska Institute \\ Eithne O'Shea \\ Karolinska Institute \\ O'Byrne James \\ Karolinska Institute
}

See next page for additional authors

Follow this and additional works at: https://arrow.tudublin.ie/scschbioart

Part of the Biochemistry Commons, and the Molecular Biology Commons

\section{Recommended Citation}

Reilly, S. J., O'Shea, E., O'Byrne, J., Alexson, S. E. H. and Hunt, M. C. (2007) A peroxisomal acyltransferase in mouse identifies a novel pathway for taurine conjugation of fatty acids. FASEB J. (2007) 21:99-107. doi:10.1096/fj06-6919

This Article is brought to you for free and open access by the School of Biological Sciences at ARROW@TU Dublin. It has been accepted for inclusion in Articles by an authorized administrator of ARROW@TU Dublin. For more information, please contact arrow.admin@tudublin.ie, aisling.coyne@tudublin.ie,gerard.connolly@tudublin.ie.

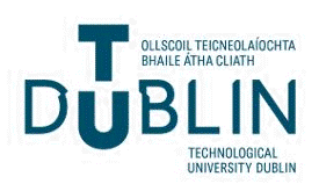




\section{Authors}

Sarah-Jayne Reilly, Eithne O'Shea, O'Byrne James, Stefan Alexson, and Mary Hunt 


\section{A peroxisomal acyltransferase in mouse identifies a novel pathway for taurine conjugation of fatty acids.}

Sarah-Jayne Reilly, Ethna M. O’Shea, Ulla Andersson, James O’Byrne, Stefan E. H. Alexson and Mary C. Hunt,

Karolinska Institutet, Department of Laboratory Medicine, Division of Clinical Chemistry C1-74, Karolinska University Hospital at Huddinge, SE-141 86 Stockholm, Sweden.

\section{Corresponding author}

Dr. Mary C. Hunt

Karolinska Institutet

Department of Laboratory Medicine

Division of Clinical Chemistry C1-74

Karolinska University Hospital at Huddinge

SE-141 86 Stockholm

Phone: +46-8-58581293

Sweden

Fax: +46-8-58581260

email: mary.hunt@ki.se

Short title: A novel fatty acid conjugating enzyme in peroxisomes 


\section{ABSTRACT}

A wide variety of endogenous carboxylic acids and xenobiotics are conjugated with amino acids, before excretion in urine or bile. The conjugation of carboxylic acids and bile acids with taurine and glycine has been widely characterized and de-novo synthesized bile acids are conjugated to either glycine or taurine in peroxisomes. Peroxisomes are also involved in the oxidation of several other lipid molecules, such as very long chain acyl-CoAs, branched chain acyl-CoAs and prostaglandins. In this study we have now identified a novel peroxisomal enzyme called acyl-CoA:amino acid $N$-acyltransferase (ACNAT1). Recombinantly expressed ACNAT1 acts as an acyltransferase that efficiently conjugates very long-chain and long-chain fatty acids to taurine. The enzyme shows no conjugating activity with glycine, showing that it is a specific taurine conjugator. Acnatl is mainly expressed in liver and kidney and the gene is localized in a gene cluster, together with two further acyltransferases, one of which conjugates bile acids to glycine and taurine. In conclusion, these data describe ACNAT1 as a new acyltransferase, involved in taurine conjugation of fatty acids in peroxisomes, identifying a novel pathway for production of $N$-acyltaurines as signaling molecules or for excretion of fatty acids.

Key words: acyl-CoA, fatty acid amide hydrolase, $\mathrm{N}$-acyltaurine. 


\section{INTRODUCTION}

The conjugation of xenobiotics to amino acids is one of the first described drug metabolizing reactions known and dates back to 1842 (1). It is now well established that a wide variety of endogenous carboxylic acids and xenobiotics are conjugated with amino acids in reactions catalyzed by different acyltransferase enzymes (2). These include both endogenous compounds like bile acids, fatty acids, and various drugs containing carboxyl groups such as clofibric acid and lovastatin (3-7). Amino acid conjugation occurs in a two-step process. The first step involves activation of the carboxylic acid to the CoA ester which is catalyzed by acyl-CoA synthetases (8). The second step, the conjugation reaction, is catalyzed by an acyl-CoA:amino acid $N$ acyltransferase (EC 2.3.1). While the conjugation of carboxylic acids and bile acids with taurine and glycine is the most common, L-asparagine and L-glutamine have also been shown to act as weak acceptors (9). The conjugation of carboxylic acids to amino acids is important as it increases the solubility of these compounds, allowing them to be excreted in urine or bile, and acts as a detoxification system for excretion of xenobiotics. The conjugation of xenobiotics is mainly linked to mitochondria and glycine conjugating enzymes have been identified in this organelle in several species (9-12). In some cases however, the metabolism of xenobiotic acyl compounds also occurs in peroxisomes (13).

Peroxisomes are organelles that are present in virtually all eukaryotic cells and are involved in the metabolism of a variety of lipids such as very long chain fatty acids, dicarboxylic acids, prostaglandins, leukotrienes, branched-chain fatty acids, xenobiotics and bile acids (14). In peroxisomes, many of these lipids are mainly 
oxidized by the peroxisomal $\beta$-oxidation system, where they are chain-shortened, with the concomitant release of acetyl-CoA. In the case of primary bile acid synthesis, trihydroxycholestanoic acid and dihydroxycholestanoic acid are activated to their corresponding CoA esters by very long chain acyl-CoA synthetase (VLCS) (15) and then undergo one cycle of $\beta$-oxidation in peroxisomes, to produce choloyl-CoA and chenodeoxycholoyl-CoA respectively (16). These bile acids are then amidated (or conjugated) to either glycine or taurine by an enzyme named bile acid-CoA:amino acid $N$-acyltransferase (BACAT). This conjugation with the amino acids glycine or taurine plays several important roles in the biology of bile acids, such as excretion of bile acids and cholesterol in bile, and increases the detergent properties of bile acids in the intestine. Recent data has shown that recombinant human BACAT can also conjugate fatty-acyl-CoAs to glycine (5) and taurine (O'Byrne et al, unpublished results).

BACAT has been characterized from several species and shows large species differences in the use of glycine or taurine as an acceptor molecule (3-5, 17). BACAT is related to a family of proteins called the Type-I acyl-CoA thioesterases (ACOTs) (for review see (18)). These ACOT enzymes show approximately 40-45\% sequence identity at amino acid level to the BACAT enzyme (3, 4). Acyl-CoA thioesterase enzymes catalyze the hydrolysis of CoA esters of fatty acids to the free fatty acid and coenzyme A (CoA), whereas BACAT conjugates bile acids and fatty acids to glycine and taurine, using the bile acid-CoA or acyl-CoA moiety as a substrate. Using Blast Searches, we have now identified a novel peroxisomal enzyme in mouse that we name acyl-CoA:amino acid $N$-acyltransferase 1 (ACNAT1), which is related to both BACAT and the Type-I ACOTs. In this study, we have 
characterized this novel peroxisomal acyltransferase and show that it efficiently conjugates long-chain fatty acids to taurine.

\section{MATERIALS AND METHODS}

Chemicals- All commercially available acyl-CoAs used in this study were from Sigma-Aldrich Inc. (St. Louis, MO, USA).

Animals and treatments- Tissues used in this study were excised from adult male Sv/129 mice. Animals were sacrificed by $\mathrm{CO}_{2}$ asphyxiation followed by cervical dislocation. Tissues were excised and stored at $-70^{\circ} \mathrm{C}$ for preparation of total RNA.

Cloning and expression of Acnat1 - The open reading frame (ORF) for Acnat1 was derived from genomic databases and expressed sequence tags (ESTs) from the mouse EST database (www.ncbi.nlm.nih.gov). The Acnatl ORF was amplified from mouse kidney total RNA using the following primers: 5'-

CTCCTCTAGAATGATGATCCAGTTGATAGC $\quad-3^{\prime} \quad$ \&
CTCCTCTAGATTAGAGTTTGCTTCCGGATTG-3' (Cybergene AB, Novum, Sweden) with the addition of Xba I sites (indicated in bold). The PCR product was cloned into the Xba I site of the pMAL-c2X vector (New England Biolabs Inc., Beverly, MA, USA) and the plasmid fully sequenced. BL21(DES3)pLysS cells (Novagen Inc., Madison, WI, USA) were transformed with the pMal-c2X and overnight cultures were transferred to $500 \mathrm{ml}$ Luria-Bertani medium containing $1 \mathrm{~g}$ of glucose and were grown at $37^{\circ} \mathrm{C}$ until an $\mathrm{OD}_{600 \mathrm{~nm}}$ of about 0.5 was reached. Protein expression was induced by addition of $0.1 \mathrm{mM}$ isopropyl-1-thio- $\beta$-D-galactopyranoside for $17 \mathrm{~h}$ at 
$20^{\circ} \mathrm{C}$ after which the bacteria were harvested by centrifugation, resuspended in $20 \mathrm{ml}$ cold column buffer (20 mM Tris- $\mathrm{HCl} \mathrm{pH} 7.4,200 \mathrm{mM} \mathrm{NaCl}, 1 \mathrm{mM}$ EDTA) and stored at $-20^{\circ} \mathrm{C}$.

Purification of recombinant ACNAT1 - Bacteria were sonicated in pulses of 12 x $5 \mathrm{sec}$ at $5 \mathrm{sec}$ intervals and centrifuged at $9,000 \mathrm{x}$ g at $4^{\circ} \mathrm{C}$ for $30 \mathrm{~min}$. The supernatant was filtered through a $0.22 \mu \mathrm{m}$ filter and recombinant protein purified using amylose resin (New England Biolabs Inc. Beverly, MA, USA). The recombinant protein was eluted with column buffer containing $10 \mathrm{mM}$ maltose.

Electrospray mass spectrometry (ES-MS) analysis- Incubation mixtures were set up containing various acyl-CoAs $(20 \mu \mathrm{M}), 5 \mu \mathrm{g}$ recombinant ACNAT1 and taurine (50 $\mathrm{mM}$ ) in $50 \mathrm{mM}$ potassium phosphate buffer, $\mathrm{pH}$ 8. Bovine serum albumin (BSA) was added in a molar ratio ranging from 1:1.2 - 1:5.7 BSA:acyl-CoA. $\mathrm{K}_{\mathrm{m}}$ and $\mathrm{V}_{\max }$ were determined using 5-50 $\mu \mathrm{M}$ palmitoyl-CoA. Incubations were carried out for $5 \mathrm{~min}$ at $37^{\circ} \mathrm{C}$ after which the samples were purified using Sepac C18 columns (International Sorbent Technologies, UK) essentially as described in (5), but the column was washed with $3 \mathrm{ml}$ water and samples eluted with $3 \mathrm{ml}$ methanol A standard of nonadecanoic acid was added to the incubation mixtures prior to column purification. The eluate was dried under nitrogen and samples reconstituted in $\sim 100 \mu$ methanol. The samples were injected into a Quattro Micro triple quadrupole mass spectrometer (Micromass, Manchester, UK) at a flow rate of $10 \mu \mathrm{l} / \mathrm{min}$. Mass spectra were acquired in the negative ion mode over a mass scan range of $\mathrm{m} / \mathrm{z} 100-1000$ for $2 \mathrm{~min}$ at a scan rate of $4 \mathrm{sec}$ per scan. 
Localization of ACNAT1 in peroxisomes using green fluorescent fusion protein and cell transfections- Oligonucleotides were designed based on the sequence of the ORF for Acnatl for cloning as a fusion protein in-frame with green fluorescent protein (GFP). The ORF of Acnatl was amplified by RT-PCR from mouse kidney total RNA using the following primers: 5'-CATATGATGATCCAGTTGATAGCC-3' and 5'CATATGTACTCTGGCATGGACACTCT-3'. PCR was performed in a PerkinElmer 2600 using the One Step RNA PCR kit (AMV) (Takara Biomedical, Shiga, Japan) and the PCR product was cloned into the pcDNA3.1/NT-GFP vector (Invitrogen), in-frame with GFP. Sequence analysis was performed using Big Dye Terminator Ready Reaction kit (Applied Biosystems Inc, CA, USA). Human skin fibroblasts from a control subject and a Zellweger patient were grown as described previously (19). The cells were grown overnight in 60-mm dishes on glass coverslips and were transfected with $10 \mu \mathrm{g}$ of ACNAT1/NT-GFP plasmid using the calcium phosphate method. The cells were fixed and processed for immunofluorescence microscopy as described in (19).

Tissue expression of Acnatl and fatty acid amide hydrolase (Faah) using Quantitative-PCR or Reverse Transcriptase-PCR- Total RNA was isolated from various mouse tissues using Trizol reagent (Invitrogen Corporation, CA, USA). Total RNA was treated with DNase 1 (Promega Corporation, Madison, WI, USA) prior to cDNA synthesis. RNA from 3 individual animals was pooled for cDNA synthesis and the synthesis was performed using $1 \mu \mathrm{g}$ of total RNA using Taqman Reverse Transcription reagents (Applied Biosystems Inc). Quantitative-PCR was performed in an ABI Prism 7000 sequence detection system, using TaqMan universal PCR master mix (Applied Biosystems Inc.). An Acnatl amplicon in the 5'- UTR was amplified 
using the following primers 5'-GAGGCAGCAACTGTGGTGACT-3' and 5'TGAGACTGTATGTTTTCCTTGCTCTAC-3' and a probe with a 5'FAM and 3'dabcyl of 5'-CGGTCATGGAGGCGGAGTGA3'. As endogenous controls an amplicon of $18 \mathrm{~S}$ and mouse $\beta$-actin was used, using the pre-developed TaqMan Assay Reagent for 18S rRNA or $\beta$-actin (Applied Biosystems Inc.). The Q-PCR was run in single-plex in triplicate for each sample. Data was analyzed using the ABI Prism 7000 SDS software and the average $C_{T}$ value per triplicate was used to calculate the relative amounts of Acnatl mRNA using the $2^{-\Delta \Delta C T}$ method. An amplicon of mouse FAAH was amplified using the following primers 5'GAAAGGCCTGGGAAGTGAACAAAG-3' and 5'CCATGGGGCCAACAGAAAG-3'. RT-PCR was carried out on total RNA from mouse tissues (pooled from three animals) using One-Step RT-PCR kit (Takara Biomedicals) using an annealing temperature of $55^{\circ} \mathrm{C}$ and 27 cycles.

\section{RESULTS}

Identification of Acnat1 - We previously identified and cloned a novel gene family of ACOTs in mouse, with members identified in cytosol (Acot1), mitochondria (Acot2) and peroxisomes (Acot3, Acot4, Acot5, Acot6) (20-23). When these genes were identified, they showed homology only to Bacat, an enzyme involved in the conjugation of bile acids. Following the advent of genome sequencing and using EST database searches, we have now identified two further genes which were mapped to mouse chromosome $4 \mathrm{~B} 3$, and found to be located in a small gene cluster within 100 $\mathrm{kb}$ with the mouse Bacat (Fig. 1A). These newly identified genes were named Acnat1 and Acnat 2 and are both encoded by 3 exons, which is similar to the exon pattern in 
Bacat and the Type-I Acot genes (20). In this study, we have characterized the ACNAT1 in detail. Alignment of the amino acid sequence of ACNAT1 to mouse BACAT shows that this protein is approximately 52\% identical to BACAT (Fig. 1B). The ACNAT1 also shows approximately $45 \%$ sequence identity to ACOT enzymes, which act as thioesterases, but is more closely related to BACAT, a conjugating enzyme. Characterization of the active site amino acids of the Type-I ACOTs and BACAT revealed a catalytic triad consisting of a nucleophilic serine residue in the ACOT enzymes (24), or a nucleophilic cysteine residue in $\operatorname{BACAT}(5,25)$, a histidine and an aspartic acid. The amino acid residues of the catalytic triad are all conserved in ACNAT1, with the ACNAT1 active site containing a serine in a SerXaaSerXaaGly motif (Fig. 1B).

ACNAT1 is localized in Peroxisomes- ACNAT1 contains the tripeptide serine-lysineleucine (-SKL) at its carboxyterminal, which is the consensus sequence of the peroxisomal type 1 targeting signal that targets proteins to peroxisomes (26). To test if ACNAT1 is indeed peroxisomal, we expressed the protein in-frame with GFP, leaving the carboxyterminal -SKL accessible. ACNAT1 was expressed in control fibroblasts and fibroblasts from a Zellweger patient, which are unable to import peroxisomal matrix proteins. Immunofluorescence microscopy revealed a punctate pattern of expression in control fibroblasts, indicative of a peroxisomal localization (Fig. 2A). When the same construct was transfected into Zellweger fibroblasts, this resulted in a diffuse GFP pattern, showing that the protein was not imported into peroxisomes but remained in cytosol (Fig. 2B). 
ACNAT1 is an acyltransferase that can conjugate fatty acids to taurine - The production of soluble protein for ACNAT1 proved difficult and following the use of several bacterial expression systems, the protein was expressed as a fusion protein with maltose binding protein (using the pMal-c2x vector), which resulted in the production of soluble protein. ACNAT1 shows homology to both BACAT and the Type-I ACOTs, and since acyl-CoAs are substrates for the Type-I ACOTs (21, 22, 24 , 27, 28) and both acyl-CoAs and bile acid-CoAs are substrates for BACAT (3-5) we hypothesized that ACNAT1 may be active on either acyl-CoAs and/or bile acidCoAs. While the Type-I ACOTs hydrolyze acyl-CoAs, BACAT conjugates fatty acids and bile acids to taurine and glycine, using the CoA moiety. Initially, incubation of recombinant ACNAT1 for $4 \mathrm{~h}$ with myristoyl-CoA $\left(\mathrm{C}_{14: 0}-\mathrm{CoA}\right)$ in the presence of taurine resulted in efficient conjugation of myristic acid to form $\mathrm{N}$-myristoyltaurine (Fig. 3A). The specificity of the reaction was verified by incubation of myristoyl-CoA and recombinant ACNAT1 in the absence of taurine, which showed no conjugation activity, but only hydrolysis of the CoA ester (Fig. 3B). Further characterization of ACNAT1 as an acyltransferase was carried out by incubating recombinant ACNAT1 for 5 min with various long-chain acyl-CoAs. ACNAT1 efficiently conjugated acylCoAs of $\mathrm{C}_{12: 0^{-}} \mathrm{CoA}$ to $\mathrm{C}_{24: 0^{-}} \mathrm{CoA}$ to taurine, suggesting that it acts as a long-chain fatty acid conjugating enzyme (Fig. 4A). Kinetic characterization of ACNAT1 was carried out using $\mathrm{C}_{16: 0}-\mathrm{CoA}$ (palmitoyl-CoA) as substrate and the $\mathrm{K}_{\mathrm{m}}$ and $\mathrm{V}_{\max }$ were determined to be $11 \mu \mathrm{M}$ and $159.5 \mathrm{nmol} / \mathrm{min} / \mathrm{mg}$, respectively (Fig. 4B). Incubation of recombinant ACNAT1 with CoA esters of the primary bile acids choloyl-CoA and chenodeoxycholoyl-CoA resulted in some conjugation of these substrates with taurine, however, this was very low compared with fatty acid conjugation (data not shown). Therefore ACNAT1 acts as an acyltransferase, conjugating very long-chain 
and long-chain fatty acids to taurine. ACNAT1 showed no conjugation activity in the presence of glycine, confirming that it is a taurine conjugating enzyme.

Tissue expression of Acnat1 and mouse Faah - Quantative PCR was carried out to examine the tissue expression of Acnat1 in mouse. Acnatl was mainly expressed in liver and kidney, with low expression in adrenal and little or no expression in other tissues examined (Fig. 5A). FAAH has previously been identified as an $\mathrm{N}$-acyltaurine hydrolyzing enzyme $(29,30)$ and we therefore examined the expression of Faah in various mouse tissues. Reverse transcriptase PCR (RT-PCR) showed that Faah was mainly expressed in liver, brain, testis and kidney (Fig. 5B), showing co-expression with Acnat1 in liver and kidney. We also examined the regulation of Acnat1 by fasting and treatment with $\mathrm{Wy}-14,643$, a peroxisome proliferator, but Acnatl was not regulated at mRNA level by either of these treatments (data not shown).

\section{DISCUSSION}

The identification of ACNAT1 is the first description of a specific fatty acid taurine conjugating enzyme and long chain acyl-CoA:amino acid $\mathrm{N}$-acyltransferase. Its identification is timely in view of the very recent detection of taurine conjugated fatty acids ( $N$-acyltaurines) as a novel class of endogenous lipids. These $N$-acyltaurines (NATs) were detected in brain, spinal cord, testes and liver of mice, using an LC-MS based analytical method termed Discovery Metabolite Profiling (DMP) (29, 30). Saghatelian et al used the DMP method to identify the physiological substrate for the fatty acid amide hydrolase (FAAH), an enzyme that degrades the endocannabinoid family of signaling lipids. The study identified metabolites that differed between 
FAAH wild-type and knockout animals and it was shown that NATs were elevated 15-40 fold in CNS tissues from FAAH knockout mice (29). The taurine conjugated fatty acids detected were mainly of 16 to 26 carbon atoms in length, with the most prevalent being $\mathrm{C}_{16: 0}, \mathrm{C}_{18: 0}, \mathrm{C}_{22: 0}$ and $\mathrm{C}_{24: 0}$ in wild type mice (29), similar to the chainlength specificity of ACNAT1 now identified. The tissue expression of the Faah in this study shows that both Acnatl and Faah are co-expressed in liver and kidney. FAAH has been shown to hydrolyze NATs back to the free fatty acid and taurine, with the activity varying depending on the chain length of the NAT, with C18:1 NAT being a better substrate for FAAH than C24 NAT $(29,30)$. This hydrolysis by FAAH could account for the low levels of NATs in-vivo, which are in the pmol/g range in brain, CNS, testes and liver, however these rise to nmol/g tissue in the CNS and spinal cord in the FAAH knockout mouse model (29). Acnatl is mainly expressed in liver and kidney and there was only very weak mRNA expression in mouse whole brain, indicating that it is unlikely that ACNAT1 produces NATs in-situ in the CNS. Alternatively these NATs may be synthesized peripherally in the liver and kidney and could then be transported to the CNS. It has been hypothesized that a similar situation could exist in relation to glycine conjugates of fatty acids ( $N$-acylglycines) and that hepatically derived NATs may be amidated by the bifunctional peptidylglycine $\alpha$ amidating enzyme ( $\alpha$-AE) and then cross the blood-brain barrier (31). Recently however, glycine conjugates of arachidonic acid have been detected in bovine and rat brain and are synthesized in-situ in rat brain as bioactive molecules that inhibit pain (32). This indicates that brain contains a distinct enzyme that can synthesize $\mathrm{N}$ acylglycines. It is not yet known if brain contains a distinct taurine conjugating enzyme responsible for synthesis of NATs in-situ in the CNS, or if these are synthesized by ACNAT1 in liver/kidney and transported to the CNS. 
The fact that ACNAT1 is a peroxisomal enzyme raises the question of the role of ACNAT1 in this organelle. Peroxisomes are associated with the metabolism of several xenobiotic acyl compounds (13), together with the $\beta$-oxidation of very longchain fatty acids, bile acid intermediates, and $\alpha$-oxidation and $\beta$-oxidation of branched chain fatty acids (33). Prostaglandins are also chain shortened in peroxisomes, followed by excretion in urine (34). Interestingly, novel taurine conjugated metabolites of prostaglandin $\mathrm{E}_{2}$ were identified in rat hepatocytes following $\beta$-oxidation (35), suggesting that partial $\beta$-oxidation of prostaglandins in peroxisomes followed by taurine conjugation of the metabolites is a means of excreting these lipids. Our finding here of a peroxisomal fatty acid taurine conjugating enzyme suggests that the entire process of partial $\beta$-oxidation followed by taurine conjugation occurs in peroxisomes. Similarly, bile acid intermediates are (side) chain shortened by $\beta$-oxidation followed by taurine (and glycine) conjugation in peroxisomes, which is the final step in de-novo bile acid synthesis and following conjugation, these bile acids are excreted into bile. Again, this conjugation results in more polar compounds for excretion and increases the detergent properties of bile acids in the intestine. Thus peroxisomal taurine conjugation of prostaglandins and bile acids results in products that are more easily excreted. In a similar way, the formation of long chain NATs by ACNAT1 in peroxisomes would also result in the production of more polar lipids for excretion. Although levels of NATs are low under normal conditions, it may be that ACNAT1 is more active under pathophysiological conditions where high levels of potentially toxic fatty acids prevail and the conjugation of these fatty acids to taurine would provide an excretory pathway in bile or urine (Fig. 6). In peroxisomes, carnitine is involved in the transfer of $\beta$-oxidation 
products to the mitochondria for further oxidation and several peroxisomal carnitine acyltransferase enzymes have been identified (36, 37), These carnitine acyltransferases have a similar catalytic mechanism to ACNAT1, by catalyzing the transfer of the acyl moiety of acyl-CoAs to carnitine, the acceptor. However, these acyltransferases are only active on medium- and short-chain fatty acids, while ACNAT1 is active on long-chain and very long-chain fatty acids. Thus the formation of NATs may also allow fatty acids to be transferred within the cell, in a similar manner to acylcarnitines. Under pathophysiological conditions when long chain acylCoAs accumulate in mitochondria, they are converted to acylcarnitines that leave the mitochondria and can readily be assayed in blood (38). Interestingly, acylcarnitines are also secreted in bile and it was shown that these bile acylcarnitines were elevated in mice deficient in mitochondrial long-chain and very long-chain acyl-CoA dehydrogenases (39). Thus, a fatty acid taurine conjugating system in peroxisomes may function in analogy to the mitochondrial carnitine acyltransferase system in mitochondria to eliminate fatty acids under conditions of fatty acid overload.

From an evolutionary point of view, ACNAT1 is related to both the BACAT enzyme and to a family of enzymes called Type-I acyl-CoA thioesterases (ACOTs) (for review see (18)) and is found in a novel gene cluster of acyltransferases on chromosome 4 B3 in mouse, together with BACAT. Several Type-I ACOT enzymes have been identified in peroxisomes and hydrolyze the acyl-CoA moiety of longchain fatty acids, medium-chain fatty acids, and succinyl-CoA, to the free acid and coenzyme A, and therefore function in terminating chain shortening of various carboxylic acids to promote transport out of the peroxisome (21-23). As stated previously, BACAT functions in the conjugation of bile acids and fatty acids to 
taurine and glycine. Therefore ACNAT1 has evolved into an enzyme that shares characteristics of both the ACOT and BACAT enzymes - it utilizes ACOT substrates (acyl-CoA) and the BACAT conjugation acceptor molecule (taurine). A further gene was identified on mouse chromosome $4 \mathrm{~B} 3$ that encodes a protein that is $92 \%$ identical to ACNAT1, which we named Acnat2. Although we have not as yet been able to identify the substrate for ACNAT2, we propose that also Acnat2 encodes an acyltransferase, given the very high percentage sequence identity to Acnat1. Thus Bacat, Acnat1 and Acnat2 comprise a novel gene cluster involved in conjugation processes for elimination of metabolites. As ACNAT1 and the ACOTs utilize the same substrate (acyl-CoAs) it is easy to envisage competitive or complementary functions for the two enzyme systems (Fig. 6). However, in general peroxisomal ACOTs show somewhat lower $\mathrm{K}_{\mathrm{m}}$-values for long-chain acyl-CoAs than ACNAT1 (4 $\mu \mathrm{M}$ for ACOT3 vs $11 \mu \mathrm{M}$ for ACNAT1 with palmitoyl-CoA), suggesting that ACNAT1 will 'kick-in' when intra-peroxisomal acyl-CoA concentrations rise. Bile acid conjugates act as ligands for the farnesoid X receptor (FXR) (40-42), a nuclear receptor involved in regulation of bile acid and carbohydrate metabolism. Fatty acids and acyl-CoAs also act as agonists/antagonists for the peroxisome proliferatoractivated receptor alpha $(\operatorname{PPAR} \alpha)(43-46)$, which regulates numerous pathways of lipid metabolism. It will be interesting to elucidate if NATs can act as agonists/antagonists for nuclear receptors and if ACNAT1 can function in controlling levels of intracellular signaling molecules.

In conclusion, we have identified ACNAT1 in mouse as a novel enzyme involved in a new pathway of taurine conjugation of fatty acids in peroxisomes. The identification of these taurine conjugates in the CNS and liver as novel metabolites (29) opens up a 
new field of research in elucidating pathways for excretion of NATs, or alternatively the discovery of new metabolic pathways for production of signaling molecules. It will be interesting to examine if these NATs can act as signaling molecules in various pathways in liver or CNS, or whether they, like glycine and taurine conjugates of bile acids, may act as agonists/antagonists for nuclear receptors. 


\section{REFERENCES}

1. Keller, W. (1842) On the conversion of benzoic acid into hippuric acid. Ann. Chem. Pharm. 43, 108

2. Vessey, D. A. (1997) Enzymes involved in the formation of amide bonds. In In Comprehensive Toxicology (Guengerich, F. P., ed) Vol. 3 pp. 455-475, Elsevier Science, Oxford, England.

3. Falany, C. N., Johnson, M. R., Barnes, S., and Diasio, R. B. (1994) Glycine and taurine conjugation of bile acids by a single enzyme. Molecular cloning and expression of human liver bile acid-CoA:amino acid N-acyltransferase. $J$. Biol. Chem. 269, 19375-19379

4. Falany, C. N., Fortinberry, H., Leiter, E. H., and Barnes, S. (1997) Cloning, expression, and chromosomal localization of moue liver bile acid-CoA:amino acid N-acyltransferase. J. Lipid Res. 38, 1139-1148

5. O'Byrne, J., Hunt, M. C., Rai, D. K., Saeki, M., and Alexson, S. E. H. (2003) The human bile acid-CoA:amino acid N-acyltransferase functions in conjugation of fatty acids to glycine. J. Biol. Chem. 278, 34237-34344

6. Halpin, R. A., Ulm, E. H., Till, A. E., Kari, P. H., Vyas, K. P., Hunninghake, D. B., and Duggan, D. E. (1993) Biotransformation of lovastatin V. species differences in In Vivo metabolite profiles of mouse, rat, dog and human. Drug Metab. Dispos. 21, 1003-1011

7. Emudianughe, T. S., Caldwell, J., Sinclair, K. A., and Smith, R. L. (1983) Species differences in the matabolic conjugation of clofibric acid and clofibrate in laboratory animals and man. Drug Metab. Dispos. 11, 97-102

8. Knights, K. M. (1998) Role of hepatic fatty acid:coenzyme A ligases in the metabolism of xenobiotic carboxylic acids. Clin. Exp. Pharmacol. Physiol. 10, 776-782

9. Nandi, D. L., Lucas, S. V., and Webster, L. T. (1979) Benzoyl-Coenzyme A:Glycine N-acyltransfrase and Phenylacetyl-Coenzyme A:glycine Nacyltransferase from bovine liver mitochondria. J. Biol. Chem. 254, 72307237

10. Kelley, M., and Vessey, D. A. (1993) Isolation and characterization of mitochondrial acyl-CoA:glycine N-acyltransferases from kidney. J. Biochem. (Tokyo) 8, 63-69

11. Mawal, Y. R., and Qureshi, I. A. (1994) Purification to homogeneity of mitochondrial acyl CoA:glycine $\mathrm{N}$-acyltransferase from human liver.

Biochem. Biophys. Res. Commun. 205, 1373-1379

12. Asaoka, K. (1991) Enzymes that metabolize acyl-coenzyme A in the monkey their distribution, properties and roles in an alternative pathway for the excretion of nitrogen. Int. J. Biochem. 23, 429-434

13. Suga, T. (2003) Drug metabolism in peroxisomes: Involvement of peroxisomal $\beta$-oxidation system in the oxidative chain-shortening of xenobiotic acyl compounds. Drug Metab. Pharmacokin. 18, 155-162

14. Van Veldhoven, P. P., and Mannaerts, G. P. (1999) Role and organization of peroxisomal $\beta$-oxidation. Adv. Exp. Med. Biol. 466, 261-272

15. Mihalik, S. J., Steinberg, S. J., Pei, Z., Park, J., Kim, D. G., Heinzer, A. K., Dacremont, G., Wanders, R. J. A., Cuebas, D. A., Smith, K. D., and Watkins, P. A. (2002) Participation of two members of the very long-chain acyl-CoA 
synthetase family in bile acid synthesis and recycling. J. Biol. Chem. 277, 24771-24779

16. Russell, D. W. (2003) The enzymes, regulation, and genetics of bile acid synthesis. Annu. Rev. Biochem. 72, 137-174

17. He, D., Barnes, S., and Falany, C. N. (2003) Rat liver bile acid CoA:amino acid $\mathrm{N}$-acyltransferase: expression, characterization, and peroxisomal localization. J. Lipid Res. 44, 2242-2249

18. Hunt, M. C., and Alexson, S. E. H. (2002) The role acyl-CoA thioesterases play in mediating intracellular lipid metabolism. Prog. Lipid Res. 41, 99-130

19. Hunt, M. C., Solaas, K., Kase, B. F., and Alexson, S. E. H. (2002) Characterization of an acyl-CoA thioesterase that functions as a major regulator of peroxisomal lipid metabolism. J. Biol. Chem. 277, 1128-1138

20. Hunt, M. C., Nousiainen, S. E. B., Huttunen, M. K., Orii, K., Svensson, L. T., and Alexson, S. E. H. (1999) Peroxisome proliferator-induced long chain acylCoA thioesterases comprise a highly conserved novel multi-gene family involved in lipid metabolism. J. Biol. Chem. 274, 34317-34326

21. Westin, M. A. K., Alexson, S. E. H., and Hunt, M. C. (2004) Molecular cloning and characterization of two mouse peroxisome proliferator-activated receptor alpha (PPAR $\alpha)$-regulated peroxisomal acyl-CoA thioesterases. $J$. Biol. Chem. 279, 21841-21848

22. Westin, M. A. K., Hunt, M. C., and Alexson, S. E. H. (2005) The identification of a succinyl-CoA thioesterase suggests a novel pathway for succinate production in peroxisomes. J. Biol. Chem. 280, 38125-38132

23. Hunt, M. C., Rautanen, A., Westin, M. A. K., Svensson, L. T., and Alexson, S. E. H. (2006) Analysis of mouse and human acyl-CoA thioesterase (ACOT) gene clusters shows that convergent functional evolution results in a reduced number of peroxisomal ACOTs. FASEB J. In press.

24. Huhtinen, K., O'Byrne, J., Lindquist, P. J. G., Contreras, J. A., and Alexson, S. E. H. (2002) The peroxisome proliferator-induced cytosolic type I acyl-CoA thioesterase (CTE-I) is a serine-histidine-aspartic acid alpha/beta hydrolase. $J$. Biol. Chem. 277, 3424-3432

25. Sfakianos, M. K., Wilson, L., Sakalian, M., Falany, C. N., and Barnes, S. (2002) Conserved residues in the putative catalytic triad of human bile acid coenzyme A:amino acid N-acyltransferase. J. Biol. Chem. 277, 47270-47275

26. Gould, S. J., Keller, G. A., Hosken, N., Wilkinson, J., and Subramani, S. (1989) A conserved tripeptide sorts proteins to peroxisomes. J. Cell Biol. 108, 1657-1664

27. Lindquist, P. J. G., Svensson, L. T., and Alexson, S. E. H. (1998) Molecular cloning of the peroxisome proliferator-induced $46-\mathrm{kDa}$ cytosolic acyl-CoA thioesterase from mouse and rat liver. Eur. J. Biochem. 251, 631-640

28. Yamada, J., Matsumoto, I., Furihata, T., Sakuma, M., and Suga, T. (1994) Purification and properties of long-chain acyl-CoA hydrolases from the liver cytosol of rats treated with peroxisome proliferator. Arch. Biochem. Biophys. 308, 118-125

29. Saghatelian, A., Trauger, S. A., Want, E. J., Hawkins, E. G., Siuzdak, G., and Cravatt, B. J. (2004) Assignment of endogenous substrates to enzymes by global metabolite profiling. Biochemistry 43, 14332-14339

30. Saghatelian, A., and Cravatt, B. J. (2005) Discovery metabolite profiling forging functional connections between the proteome and metabolome. Life Sciences 77, 1759-1766 
31. Wilcox, B. J., Ritenour-Rodgers, K. J., Asser, A. S., Baumgart, L. E., Baumgart, M. A., Boger, D. L., DeBlassio, J. L., deLong, M. A., Gluke, U., Henz, M. E., King III, L., Merkler, K. A., Patterson, J. E., Robleski, J. J., Vederas, J. C., and Merkler, D. J. (1999) N-acylglycine amidation: Implications for the biosynthesis of fatty acid primary amides. Biochemistry 38, 3235-3245

32. Huang, S. M., Bisogno, T., Petros, T. J., Chang, S. Y., Zavitsanos, P. A., Zipkin, R. E., Sivakumar, R., Coop, A., Maeda, D. Y., De Petrocellis, L., Burstein, S., Di Marzo, V., and Walker, J. M. (2001) Identification of a new class of molecules, the arachidonyl amino acids, and characterization of one member that inhibits pain. J. Biol. Chem. 276, 42639-42644

33. Wanders, R. J. A. (2004) Peroxisomes, lipid metabolism, and peroxisomal disorders. Mol. Genet. Metab. 83, 16-27

34. Diczfalusy, U., Kase, B. F., Alexson, S. E. H., and Björkhem, I. (1991) Metabolism of prostaglandin $\mathrm{F}_{2 \alpha}$ in Zellweger syndrome. Peroxisomal betaoxidation is a major importance for in vivo degradation of prostaglandins in humans. J. Clin. Invest. 88, 978-984

35. Hankin, J. A., Wheelan, P., and Murphy, R. C. (1997) Identification of novel metabolites of prostaglandin $\mathrm{E}_{2}$ formed by isolated rat hepatocytes. Arch. Biochem. Biophys. 340, 317-330

36. Ferdinandusse, S., Mulders, J., IJlst, L., Denis, S., Dacremont, G., Waterham, H. R., and Wanders, R. J. A. (1999) Molecular cloning and expression of human carnitine octanoyltransferase: evidence for its role in the peroxisomal $\beta$-oxidation of branched-chain fatty acids. Biochem. Biophys. Res. Commun. 263, 213-218

37. Farrell, S. O., Fiol, C. J., Reddy, J. K., and Bieber, L. L. (1984) Properties of purified carnitine acyltransferases of mouse liver peroxisomes. J. Biol. Chem. 259, 13089-13095

38. Spiekerkoetter, U., Tokunaga, C., Wendel, U., Mayatepek, E., Exil, V., Duran, M., Wijburg, F. A., Wanders, R. J. A., and Strauss, A. W. (2004) Changes in blood carnitine and acylcarnitine profiles of very long-chain acyl-CoA dehydrogenase-deficient mice subjected to stress. Eur. J. Clin. Invest. 34, 191196

39. Cox, K. B., Hamm, D. A., Millington, D. S., Matern, D., Vockley, J., Rinaldo, P., Pinkert, C. A., Rhead, W. J., Russell Lindsey, J., and Wood, P. A. (2001)

Gestational, pathologic and biochemical differences between very long-chain acyl-CoA dehydrogenase deficiency and long-chain acyl-CoA dehydrogenase deficiency in the mouse. Hum. Mol. Genet. 10, 2069-2077

40. Parks, D. J., Blanchard, S. G., Bledsoe, R. K., Chandra, G., Consler, T. G., Kliewer, S. A., Stimmel, J. B., Willson, T. M., Zavacki, A. M., Moore, D. D., and Lehmann, J. M. (1999) Bile acids: natural ligands for an orphan nuclear receptor. Science 284, 1285-1286

41. Wang, H., Chen, J., Holoister, K., Sowers, L. C., and Forman, B. M. (1999) Endogenous bile acids are ligands for the nuclear receptor FXR/BAR. Mol. Cell 5, 543-553

42. Makishima, M., Okamoto, A. Y., Repa, J. J., Tu, H., Learned, R. M., Luk, A., Hull, M. V., Lustig, K. D., Mangelsdorf, D. J., and Shan, B. (1999) Identification of a nuclear receptor for bile acids. Science 284, 362-365

43. Kliewer, S. A., Sundseth, S. S., Jones, S. A., Brown, P. J., Wisely, G. B., Koble, C. S., Devchand, P., Wahli, W., Willson, T. M., Lenhard, J. M., and 
Lehmann, J. M. (1997) Fatty acids and eicosanoids regulate gene expression through direct interactions with peroxisome proliferator-activated receptors $\alpha$ and $\gamma$. Proc. Natl. Acad. Sci. U.S.A. 94, 4318-4323

44. Forman, B. M., Chen, J., and Evans, R. M. (1997) Hypolipidemic drugs, polyunstaurated fatty acids, and eicosanoids are ligands for peroxisome proliferator-activated receptors $\alpha$ and $\delta$. Proc. Natl. Acad. Sci. U.S.A. 94, 4312-4317

45. Göttlicher, M., Widmark, E., Li, Q., and Gustafsson, J. Å. (1992) Fatty acids activate a chimera of the clofibric acid-activated receptor and the glucocorticoid receptor. Proc. Natl. Acad. Sci. U.S.A. 89, 4653-4657

46. Hostetler, H. A., Petrescu, A. D., Kier, A. B., and Schroeder, F. (2005) Peroxisome proliferator-activated receptor $\alpha($ PPAR $\alpha)$ interacts with high affinity and is conformationally responsive to endogenous ligands. J. Biol. Chem. 280, 18667-18682 


\section{Acknowledgements:}

We thank Seamus Browne for discussions on protein expression systems. This study is supported by the FP6 European Union Project 'Peroxisome' (LSHG-CT-2004512018), the Swedish Research Council, Svenska Sällskapet för Medicinsk Forskning, AFA sjukförsäkrings jubileumsstiftelse, Åke Wibergs stiftelse, HjärtLungfonden, Lars Hiertas Minne, Fredrik och Ingrid Thurings Stiftelse, Ruth och Richard Julins Stiftelse, Stiftelsen Professor Nanna Svartz fond and Stiftelsen Goljes minne. 


\section{FIGURE LEGENDS}

Fig. 1. Sequence alignment and chromosomal localization of acyl-CoA:amino acid $N$-acyltransferase (Acnat1) and bile acid-CoA:amino acid $N$-acyltransferase

(Bacat). (A) Database searches identified three related genes in a cluster on mouse chromosome 4 B3 within $100 \mathrm{~kb}$ of DNA. Acnat1 and Acnat2 (acyl-CoA:amino acid $\mathrm{N}$-acyltransferase) and Bacat (bile acid-CoA:amino acid $\mathrm{N}$-acyltransferase). Each gene is coded by three exons. (B) Alignment of ACNAT1 and BACAT amino acid sequences. ACNAT1 contains a peroxisomal type 1 targeting signal of serine-lysineleucine (-SKL) at the carboxyterminal end. An active site serine is found at position 235, an aspartate residue at position 325 and a histidine at position 359 of ACNAT1, which are marked with closed triangles, and constitute the putative catalytic triad.

\section{Fig. 2. ACNAT1 is localized in peroxisomes.}

The open reading frame of Acnatl was cloned in-frame with green fluorescent protein (GFP) and expressed in either control human skin fibroblasts, or fibroblasts from a Zellweger patient. Immunofluorescence microscopy was carried out using a Tritclabeled anti-GFP antibody. (A) Punctate expression of ACNAT1 in control fibroblasts. (B) Diffuse expression of ACNAT1 in Zellweger fibroblasts.

Fig. 3. ACNAT1 is an acyltransferase. Recombinant ACNAT1 (20 $\mu \mathrm{g})$ was incubated for $4 \mathrm{~h}$ with $50 \mu \mathrm{M}$ myristoyl-CoA in the presence (A) or absence (B) of 50 $\mathrm{mM}$ taurine and the incubations were analyzed by ES-MS. The peak at 334.11 corresponds to $N$-myristoyltaurine, the peak at 297.1 corresponds to nonadecanoic 
acid added as an internal standard and the peak at 227.11 corresponds to myristic acid.

Fig. 4. ACNAT1 is an acyltransferase that conjugates fatty acids to taurine.

(A) Recombinant ACNAT1 $(5 \mu \mathrm{g})$ was incubated for 5 min with $20 \mu \mathrm{M}$ of various acyl-CoAs with the addition of bovine serum albumin (BSA) in a molar ratio of between 1:1.2 and 1:5.7 BSA:acyl-CoA, in the presence $50 \mathrm{mM}$ taurine. Nonadecanoic acid $(20 \mu \mathrm{M})$ was added as an internal standard and the samples were analyzed by ES-MS and quantified with respect to the internal standard and taurine conjugates formed. The amount of taurine conjugated fatty acid formed was calculated in nmol/min/mg. (B) Recombinant ACNAT1 (5 $\mu \mathrm{g}$ ) was incubated for 2 min at various concentrations of $\mathrm{C}_{16: 0} \mathrm{CoA}(5-50 \mu \mathrm{M})$ with the addition of bovine serum albumin (BSA) in a molar ratio of 1:2.3 BSA:acyl-CoA, and $50 \mathrm{mM}$ taurine. Nonadecanoic acid $(5 \mu \mathrm{M})$ was added as an internal standard and the samples were analyzed by ES-MS and quantified with respect to the internal standard. $\mathrm{K}_{\mathrm{m}}$ and $\mathrm{V}_{\max }$ were determined using Sigma Plot Enzyme Kinetics Program.

\section{Fig. 5: Acnat1 and Faah tissue expression in mouse.}

(A) The tissue expression of Acnatl was investigated in mouse tissues using singleplex Q-PCR. Total RNA was prepared from 3 animals, which was pooled for each tissue and cDNA was prepared from the pooled RNA samples. Q-PCR was run in triplicate for each tissue, using $18 \mathrm{~S}$ and $\beta$-actin mRNA as a control and the relative amounts of mRNA were calculated using the $2^{-\Delta \Delta \mathrm{CT}}$ method. BAT; brown adipose tissue; WAT; white adipose tissue; proximal intestine (first $10 \mathrm{~cm}$ of small intestine); distal intestine (last $10 \mathrm{~cm}$ of the small intestine). (B) Total RNA was prepared from 3 
animals and pooled. Reverse-transcriptase PCR with fatty acid amide hydrolase (Faah) primers was carried out on $1 \mu \mathrm{g}$ pooled total RNA. PCR products were analyzed on a $2 \%$ agarose gel stained with ethidium bromide. $\beta$-actin was included as a positive control.

Fig. 6: Role of ACNAT1 and acyl-CoA thioesterases (ACOTs) in peroxisomal fatty acid $\beta$-oxidation. The peroxisomal $\beta$-oxidation acts as a chain shortening system. Due to the presence of multiple acyl-CoA thioesterases (ACOTs) , $\beta$ oxidation intermediates may be removed from the pathway. Under conditions when intra-peroxisomal acyl-CoA concentrations increase (either from uptake or increased levels of $\beta$-oxidation intermediates), acyl-CoA thioesterases (mainly ACOT3, ACOT5 and ACOT8) hydrolyze medium- and long-chain acyl-CoAs to the free acid and CoASH. The non-esterified fatty acids may exit the peroxisome and re-enter the $\beta$-oxidation pathway after activation to the CoA-ester by the long-chain acyl-CoA synthetase (LACS) located at the matrix side of the peroxisomal membrane. Alternatively, acyl-CoAs are substrate for ACNAT1, which in the presence of taurine, conjugates the fatty acid moiety to taurine to produce the $\mathrm{N}$-acyltaurines. These $\mathrm{N}$ acyltaurines (e.g. N-palmitoyltaurine) exit the peroxisome and may act as signaling molecules in the liver or kidney or may be sent out in the blood for distribution to other organs or alternatively excreted in bile or urine.

This sequence was deposited under Genbank Accession Number DQ469311. 


\section{Chromosome 4 B3}

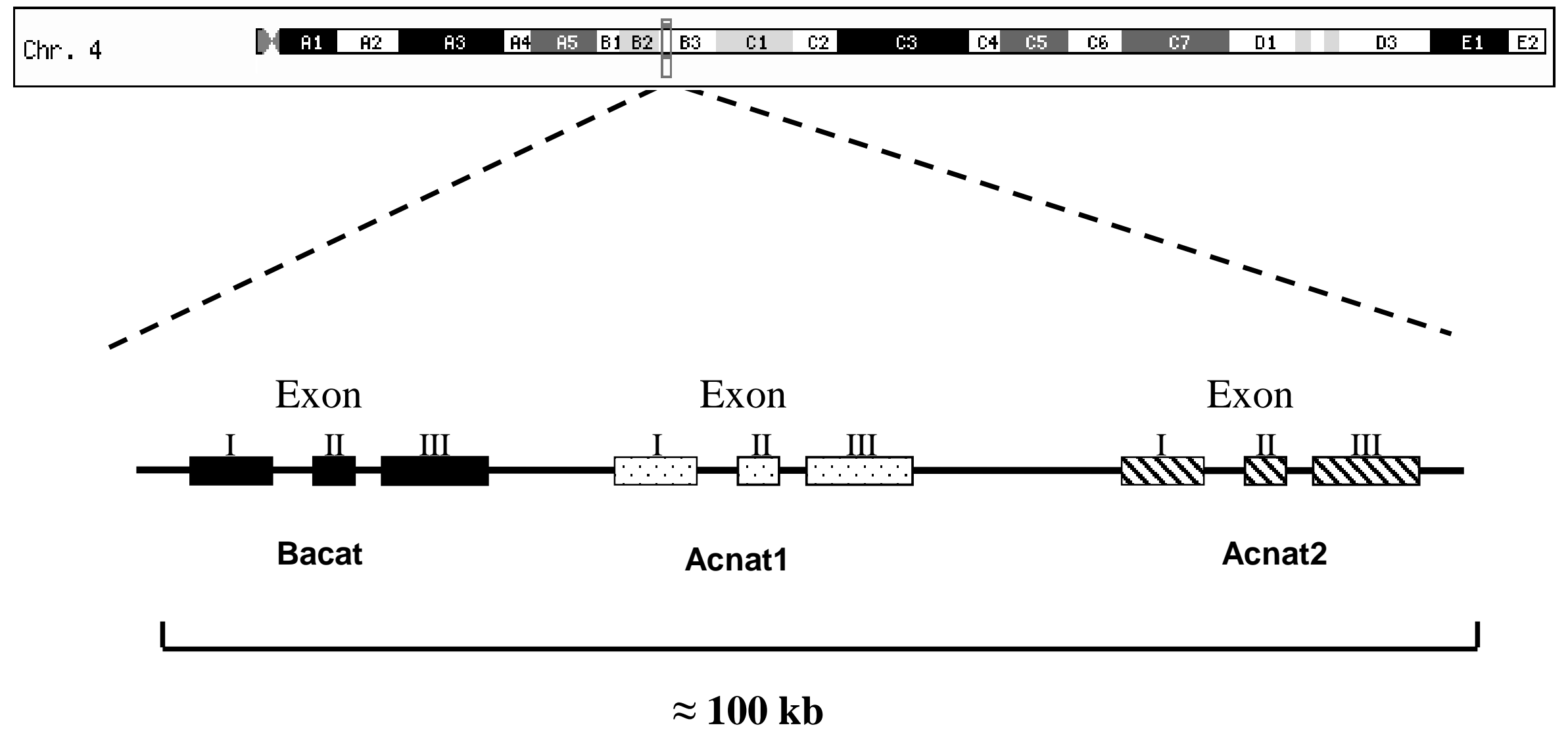




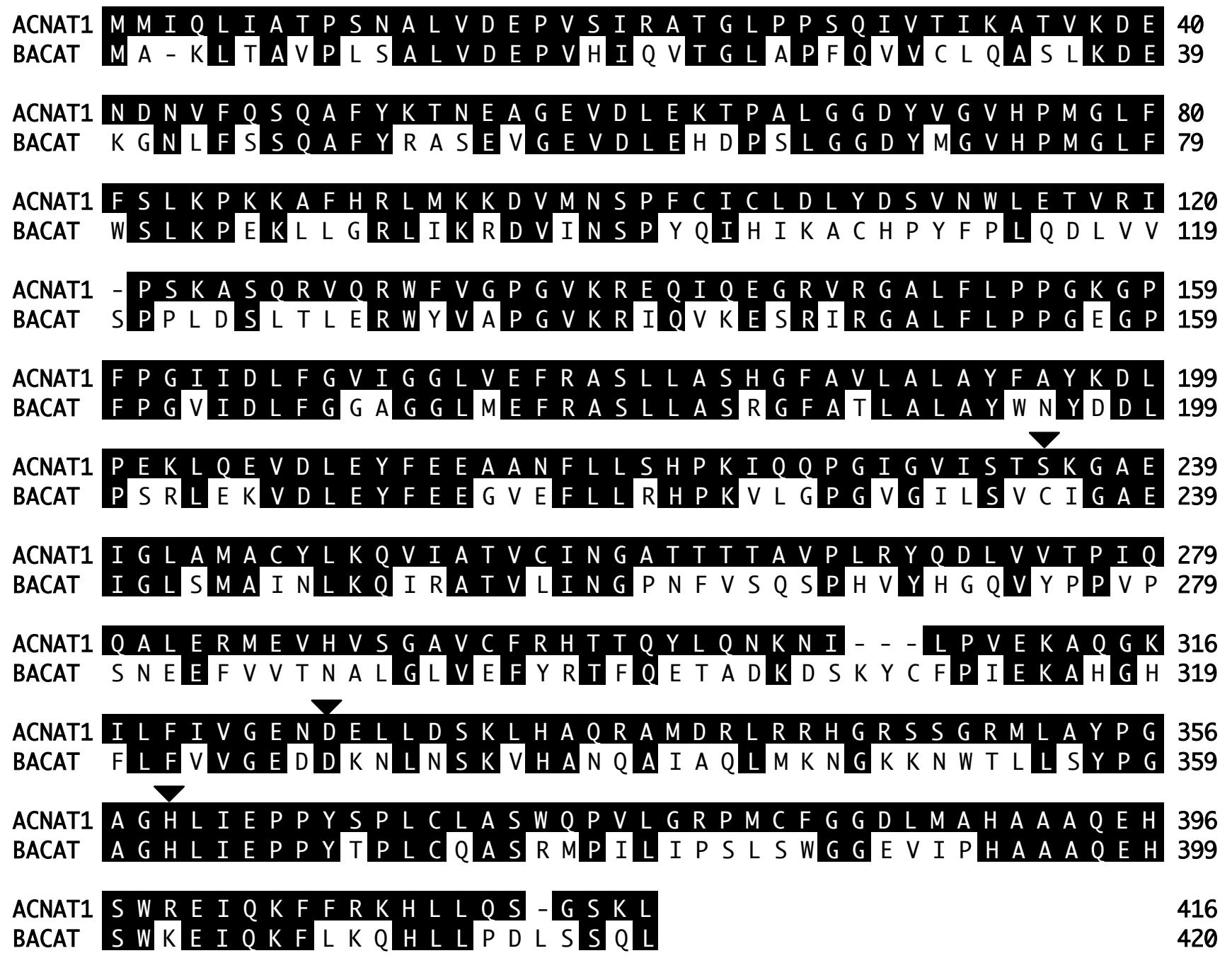


A

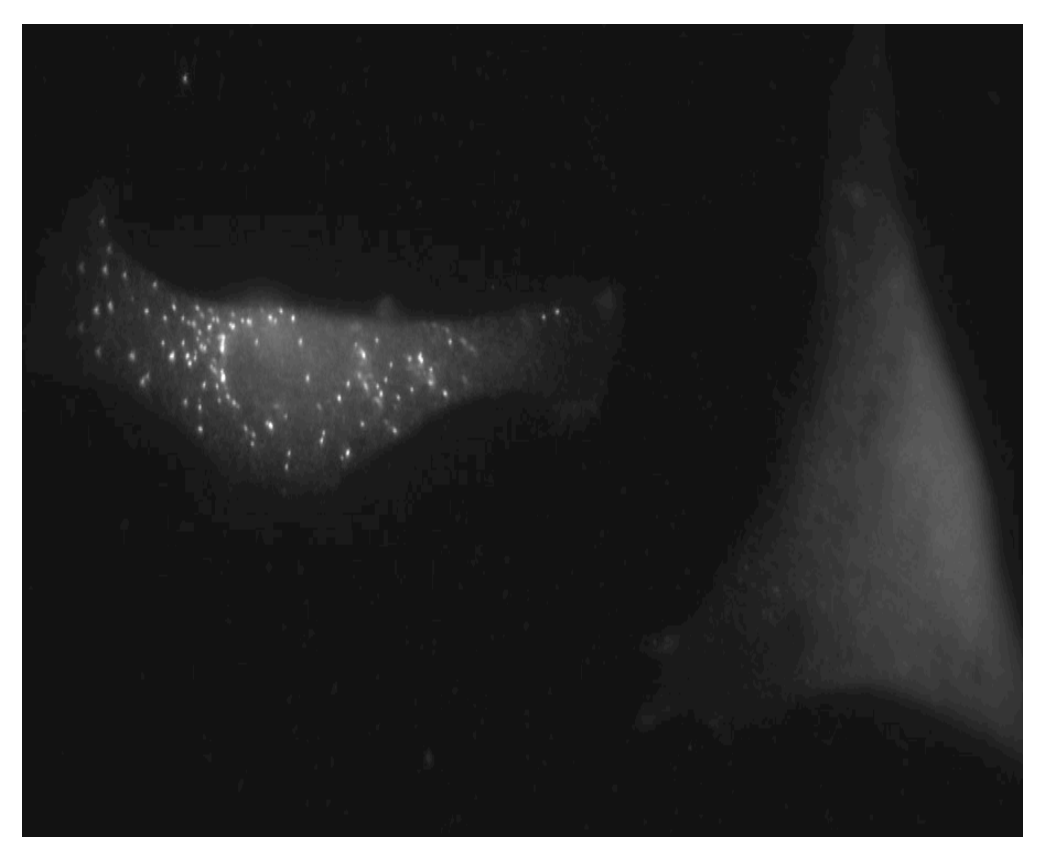

B

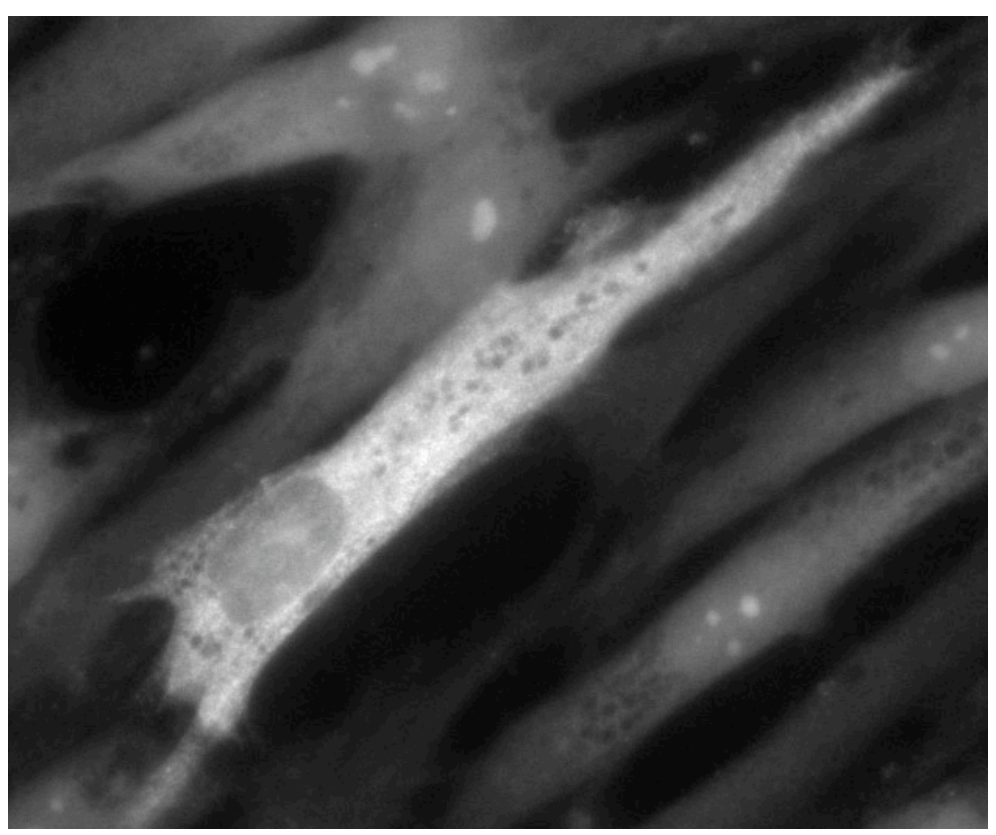


Reilly et al

Fig. 3

A

B

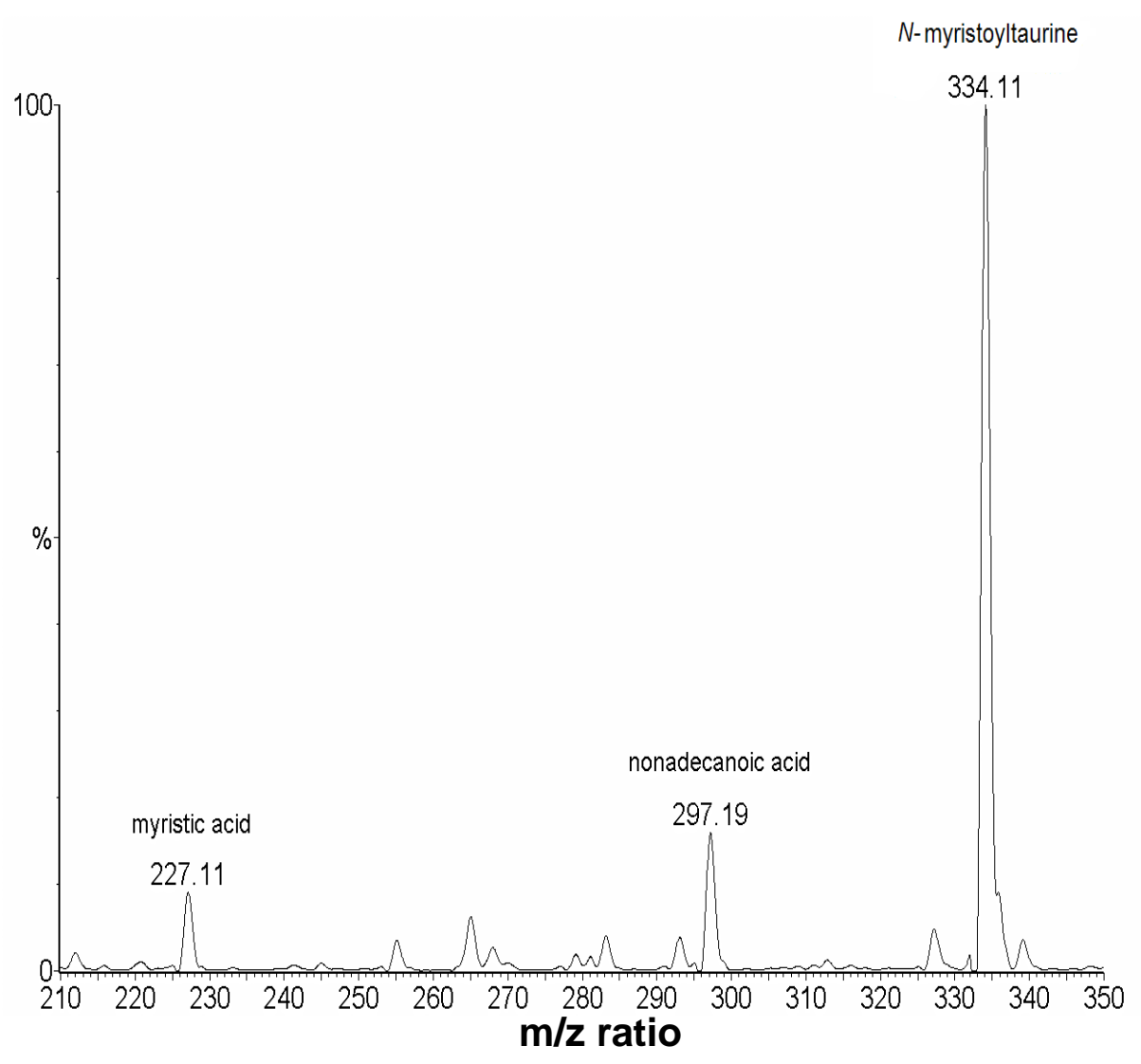

+ Taurine

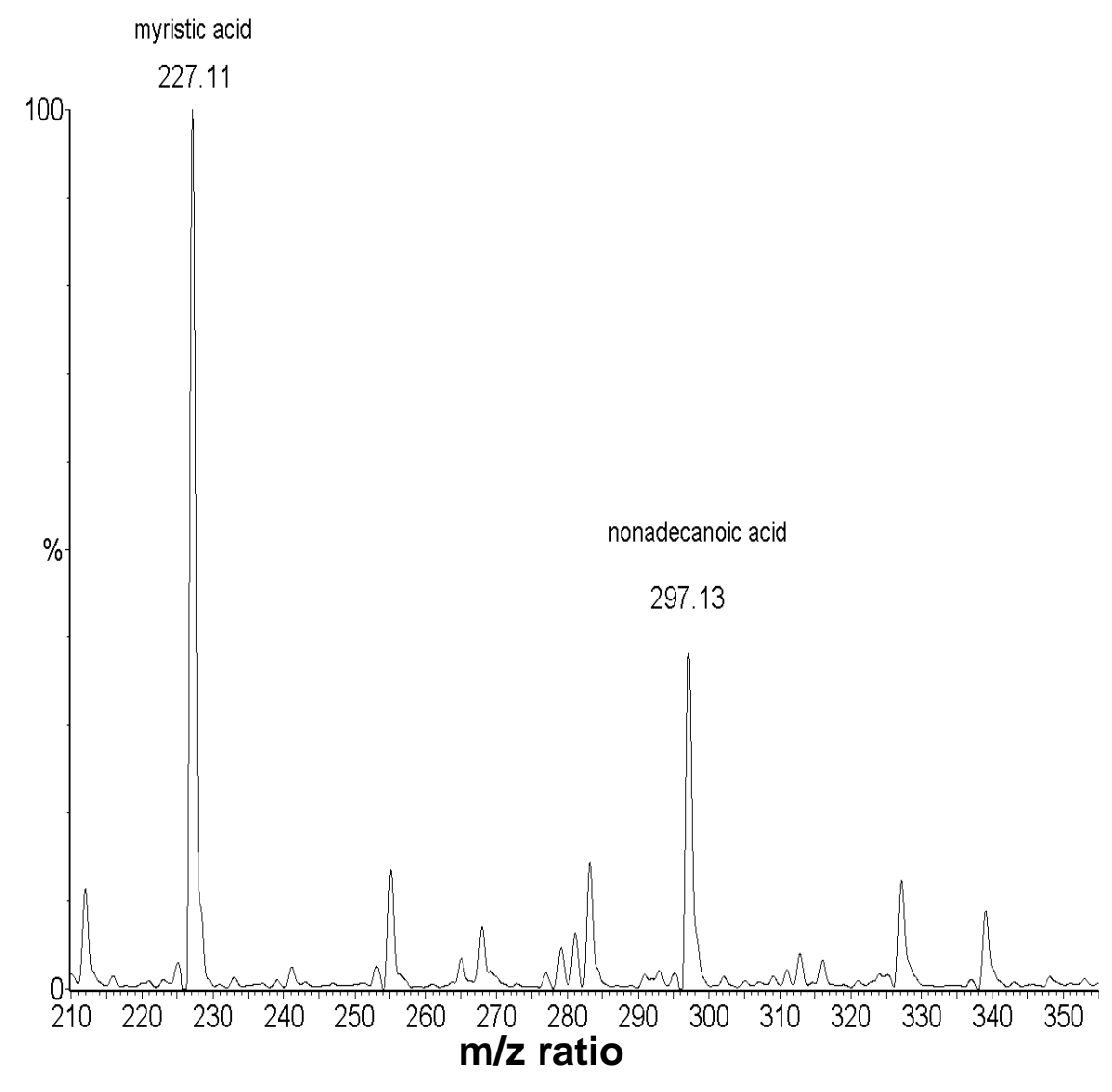

- Taurine 


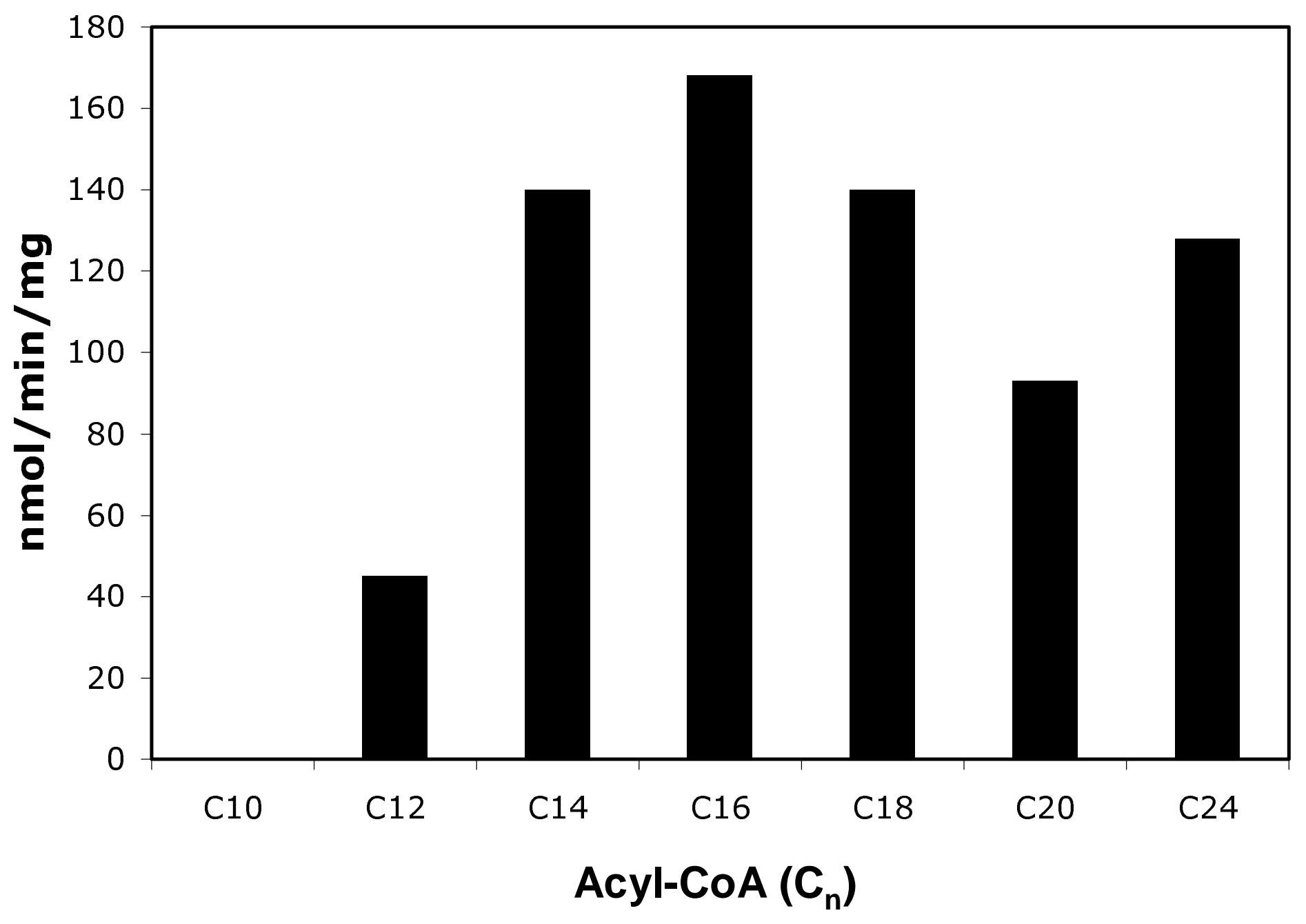


Reilly et al

Fig. 4

B

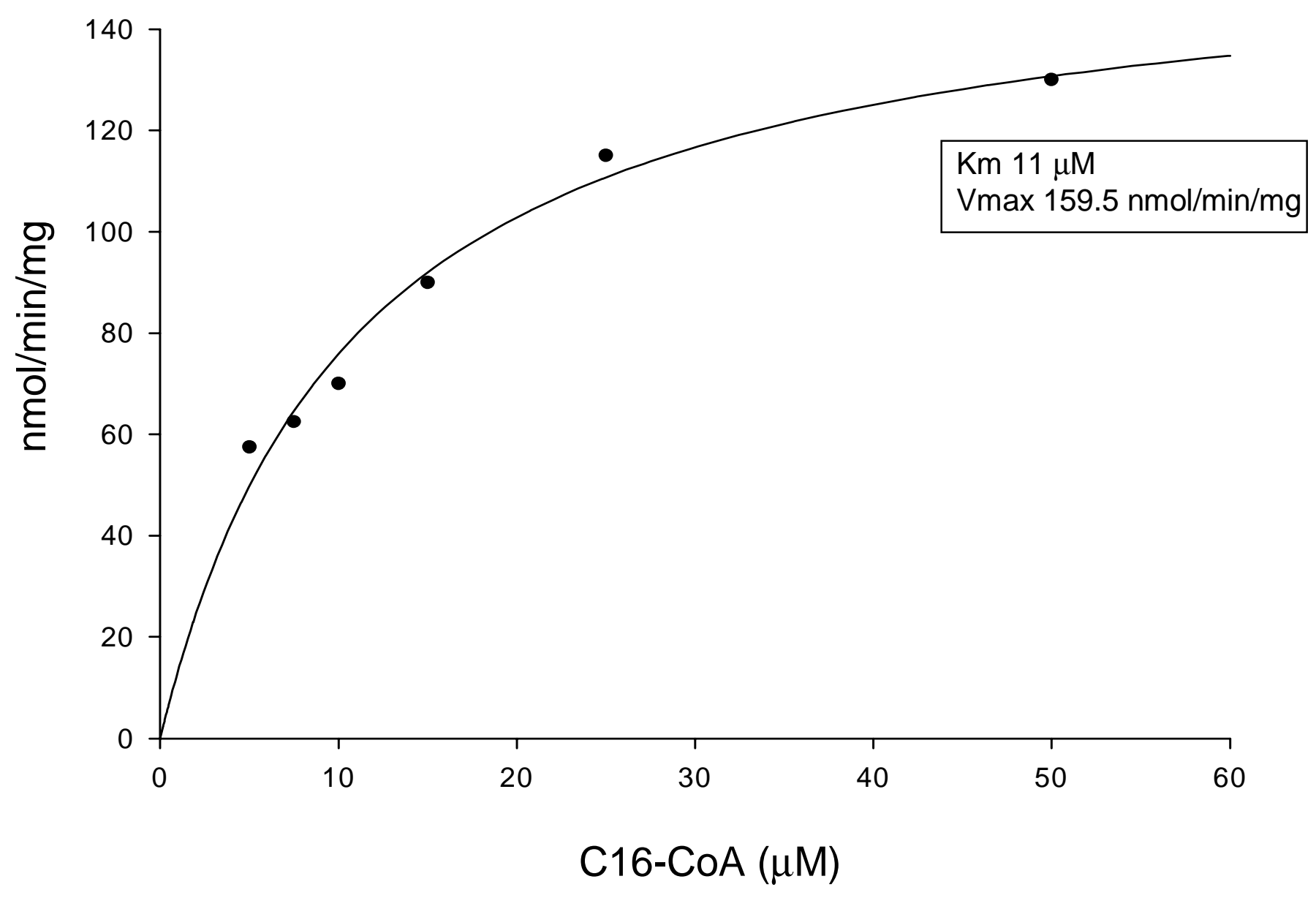


Reilly et al

Fig.5

A

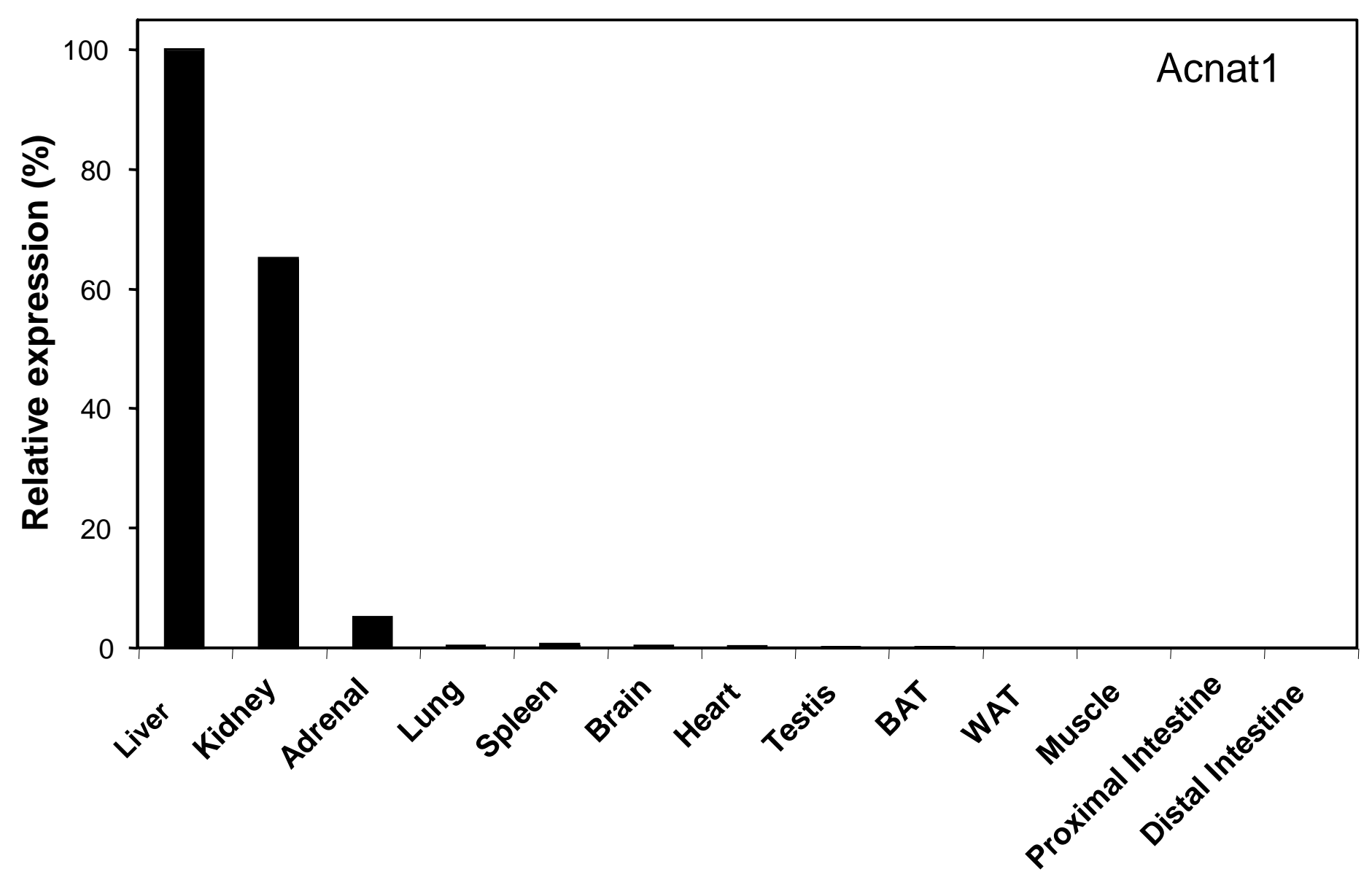


Reilly et al

Fig.5

B

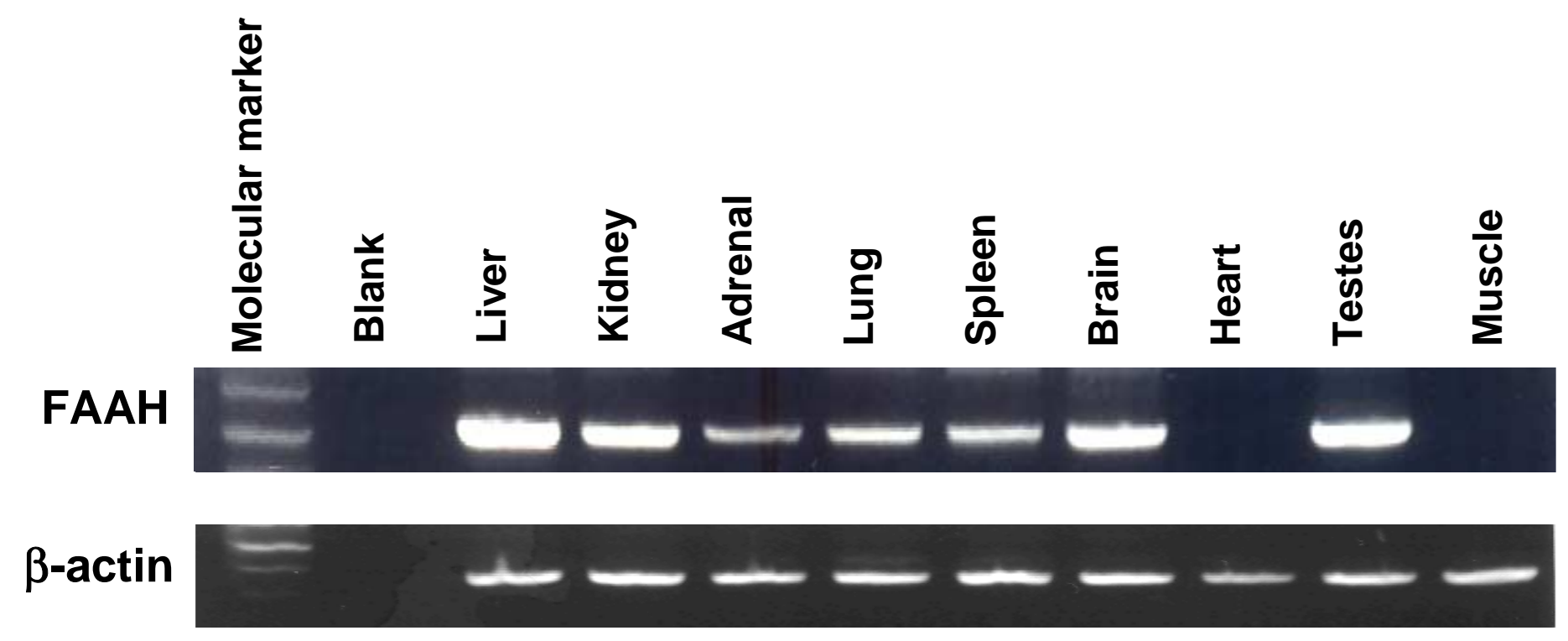




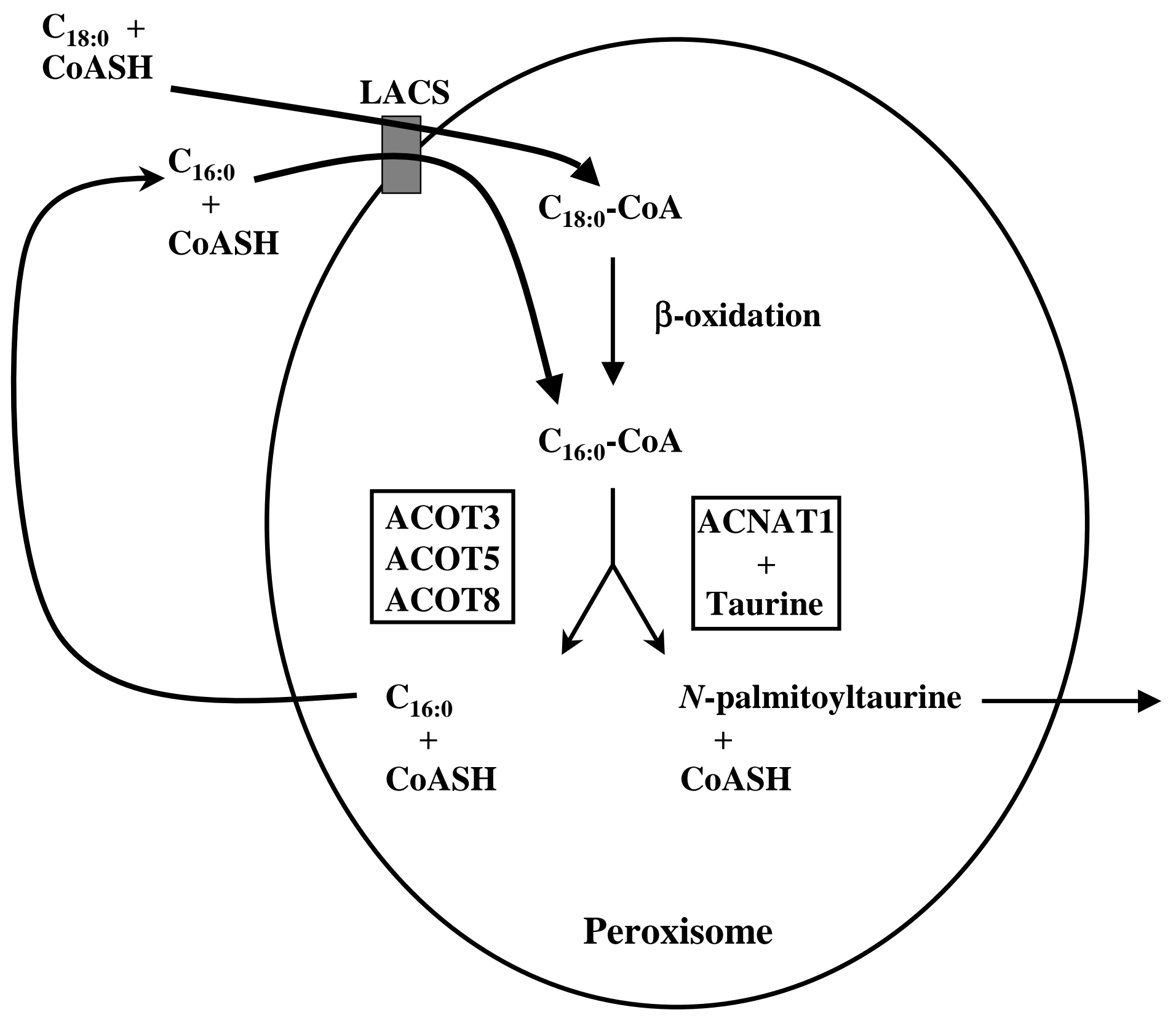

Cell signaling. To Blood. Excretion in bile or urine. 